\title{
Novel Preoperative Patient-centered Surgical Wellness Program Impacts Length of Stay Following Pancreatectomy
}

\author{
MAZHAR SOUFI ${ }^{1,2^{*}}$, DANIELLE K. DEPERALTA ${ }^{1 *}$, RACHEL SIMPSON $^{1,2}$, KATELYN FLICK $^{1,2}$, \\ MICHELE T. YIP-SCHNEIDER ${ }^{1,2,3,4}$, CHRISTIAN M. SCHMIDT II ${ }^{1,2}$, MOLLY KILBANE $^{5}$, \\ CAMERON COLGATE ${ }^{1}$, KRISTEN E. KELLEY ${ }^{5}$, WILLIAM WOODEN ${ }^{1}$, EUGENE P. CEPPA ${ }^{1,2}$, \\ MICHAEL HOUSE ${ }^{1}$, NICHOLAS ZYROMSKI ${ }^{1}$, ATILLA NAKEEB ${ }^{1}$ and C. MAX SCHMIDT ${ }^{1,2,3,4}$ \\ ${ }^{1}$ Department of Surgery, Indiana University School of Medicine, Indianapolis, IN, U.S.A.; \\ ${ }^{2}$ Indiana University Health Pancreatic Cyst and Cancer Early Detection Center, Indianapolis, IN, U.S.A.; \\ ${ }^{3}$ Walther Oncology Center, Indianapolis, IN, U.S.A.; \\ ${ }^{4}$ Indiana University Simon Cancer Center, Indianapolis, IN, U.S.A.; \\ ${ }^{5}$ Infection Prevention, Indiana University Health, Indianapolis, IN, U.S.A.
}

\begin{abstract}
Background/Aim: We created a novel, preoperative wellness program (WP) that promotes recovery. This study assessed its impact on patient outcomes after pancreatectomy. Patients and Methods: Pancreatoduodenectomies (PD) and distal pancreatectomies (DP) performed from 2015 to 2018 were reviewed using our institutional NSQIP database. Patients in the WP had their medical conditions optimized and were provided with the following: chlorhexidine, topical mupirocin, incentive spirometer, and immune-nutrition supplements. Results: Out of a total of 669 pancreatectomy patients (411 PD, 258 DP), 308 were enrolled in the WP (188 $P D, 120 \mathrm{DP})$. In the PD subgroup, on multivariable analysis (MVA), the WP patients had shorter lengths of hospital stay (LOS) ( 12 vs. 10 days, $p<0.001)$. On MVA, WP patients had less post-op transfusion (20 vs. 10\%, $p=0.027$ ). For the combined groups on MVA, LOS continued to be significant $(O R=0.89,95 \% C I=0.82-0.97, p<0.007)$. Conclusion: A preoperative patient centered WP may reduce the length of stay.
\end{abstract}

Pancreaticoduodenectomy (PD) is a high-risk procedure. In 1935, Whipple et al. reported the first case series, describing a two-stage procedure, with associated morbidity of $90 \%$ and

This article is freely accessible online.

*These Authors contributed equally to this work.

Correspondence to: C. Max Schmidt, MD, Ph.D., MBA, FACS, Department of Surgery, Indiana University School of Medicine, 545 Barnhill Drive, Emerson Hall 129, Indianapolis, IN 46202, U.S.A. Tel: +1 3179488358, e-mail: maxschmi@iupui.edu

Key Words: Preoperative care, pancreatectomy, enhanced recovery, length of stay. mortality rate approaching 29\% (1). The safety profile of PD has dramatically improved with high-volume centers reporting morbidity rates of $40-60 \%$ and mortality rates of $2-4 \%(2-4)$. Beyond allocation of complex pancreatic surgery to highvolume centers, several interventions have proven effective in reducing morbidity associated with pancreatectomy.

Healthcare associated infections (HAIs) affect $4 \%$ of hospitalized patients $(5,6)$, of which $20 \%$ are surgical site infections (SSIs). SSI is the most common surgical complication, with an incidence of 2-5\% following inpatient operations (6), and up to $28 \%$ following complex gastrointestinal procedures (3-5). SSI is associated with increased length of stay (LOS), readmission, and an estimated national financial burden of 3-10 billion dollars $(6,7)$. SSIs are thought to be preventable in up to $60 \%$ of cases with adherence to current guidelines $(6,8,9)$. These include the use of surgical clippers, chlorhexidine scrub, preoperative antibiotics, and nutritional optimization. Methicillin resistant staph aureus (MRSA) is the most common pathogen involved in SSIs from non-colorectal surgical procedures. Preoperative decolonization with topical mupirocin and chlorhexidine gluconate bath scrub decreases MRSA-associated SSI $(6,8,9)$.

Smoking cessation has also been associated with decreased SSI and post-operative pulmonary complications (10). Other simple measures include incentive spirometry, ambulation, and increased physical activity in the peri-operative period $(11,12)$. Finally, poor nutritional status is associated with increased post-operative complications, poor wound healing and decreased functional quality of life (13). Nutritional optimization in the preoperative setting can replenish micronutrient deficiencies, provide a positive nitrogen balance, and optimize the immune response $(14,15)$.

At a single high-volume academic medical center, a preoperative patient-centered surgical wellness program (WP) 
was launched. This program was part of an institutional initiative to improve postoperative patient outcomes. The objective of this study was to assess the impact of the WP on patient outcomes following pancreatic resection.

\section{Patients and Methods}

Description of the intervention. As part of an effort to improve surgical outcomes, a WP was launched in January 2016. Prior to its launch, patient feedback was an important element in designing clear and concise instructions for the WP. The WP typically starts with a patient's referral by their surgeon. The WP consists of a visit to the preadmission testing (PAT) Clinic where acute/chronic medical conditions are identified, and referrals are made for testing or to medical subspecialty clinics where indicated. Patients are also educated on the benefits of increasing daily baseline physical activities, smoking/alcohol cessation, and the following bundled components: mupirocin topically for the nares, chlorhexidine bath scrub, an incentive spirometer, and immune-nutrition supplements [Impact Advanced Recovery ${ }^{\circledR}$ (AR) drink]. These components were bundled into a sporty, red, roller bag provided to patients without cost. Patients who did not get referred for the WP, did not visit PAT Clinic and did not receive the red roller bag with bundled components. These patients were the control group. Approximately $46 \%$ of patients that underwent pancreatic resection were enrolled in the WP. The PAT visit took place between 3-40 days prior to surgery (average 2 weeks).

Patient population. Between June 2015-June 2018, a total of 669 patients underwent pancreatectomy (411 PD, $258 \mathrm{DP})$. Of these, $46 \%$ ( $n=308 ; 188$ PD, 120 DP) were enrolled in the WP. Using the institutions prospectively gathered National Surgical Quality Improvement Program (NSQIP) database, a retrospective review was performed. Patients were categorized into 2 groups: those enrolled in the WP and those who were not (control group). Patient demographics, comorbidities, and outcomes including complications were noted.

Variables of interest. Outcomes data were collected from medical records, patient surveys, as well as staff feedback. Outcome variables of interest included surgical site infection SSI, clinical documented improvement (CDI), ventilation associated events (VAE), MRSA, postoperative pancreatic fistula (POPF), delayed gastric emptying (DGE), as well as patient safety indicators PSI-90. PSI-90 is a nationally recognized quality measure. Although some of the PSI-90 variables were irrelevant to the study (incidental puncture, laceration, pneumothorax), they constituted only a small percentage of the data presented, with most of the cases coming from relevant indicators such as post-operative respiratory failure, sepsis, wound infection, and acute kidney injury. The international study group of pancreatic surgery (ISGPS) updated 2016 criteria, were used to define DGE and POPF, respectively $(16,17)$. Outcomes per individual wellness component compliance were not analyzed due to lack of quality data and inadequate statistical power. The Indiana University Institutional Review Board approved the conduct of this study, and data storage was compliant with the Health Insurance Portability and Accountability Act.

Compliance. All patients enrolled in the WP were referred and seen in the PAT Clinic, underwent a medical evaluation and received
Table I. Comparison of demographics and perioperative variables for PD patients with and without enrollment in the WP program.

\begin{tabular}{|c|c|c|c|}
\hline \multirow[b]{2}{*}{ Covariate } & \multicolumn{2}{|c|}{ PD Patients only } & \multirow[b]{2}{*}{$p$-Value } \\
\hline & $\begin{array}{c}\text { Non-WP } \\
(\mathrm{n}=223) \\
\mathrm{n}(\%) \text { or } \\
\text { mean (SD) }\end{array}$ & $\begin{array}{c}\text { WP } \\
(\mathrm{n}=188) \\
\mathrm{n}(\%) \text { or } \\
\text { mean (SD) }\end{array}$ & \\
\hline Age & $65.33(13.16)$ & $63.65(12.15)$ & 0.158 \\
\hline BMI & $27.01(6.06)$ & $27.79(5.63)$ & 0.116 \\
\hline Gender (male) & $111(49.8)$ & $90(47.9)$ & 0.770 \\
\hline Race (non-white) & $20(9)$ & $15(8)$ & 0.731 \\
\hline Diabetes & $54(24.2)$ & $55(29.3)$ & 0.263 \\
\hline Hypertension & $131(58.7)$ & $105(55.9)$ & 0.619 \\
\hline Steroid/Immunosuppressant use & $3(1.3)$ & $6(3.2)$ & 0.311 \\
\hline Weight loss $>10 \%$ & $44(19.7)$ & $42(22.3)$ & 0.545 \\
\hline Received preop transfusion(s) & $5(2.2)$ & $0(0)$ & 0.066 \\
\hline Open operative approach & $223(100)$ & $185(98.4)$ & 0.093 \\
\hline Soft gland & $109(52.2)$ & $82(44.6)$ & 0.154 \\
\hline Pancreatic duct size & & & 0.209 \\
\hline$<3 \mathrm{~mm}$ & $35(15.7)$ & 39 (20.7) & \\
\hline $3-6 \mathrm{~mm}$ & $149(66.8)$ & $111(59.0)$ & \\
\hline$>6 \mathrm{~mm}$ & $26(11.7)$ & $30(16.0)$ & \\
\hline Preop obstructive jaundice & $80(35.9)$ & $59(31.4)$ & 0.350 \\
\hline Preop biliary stenting & $114(51.1)$ & $106(56.4)$ & 0.320 \\
\hline Preop chemotherapy & $30(13.5)$ & $39(20.7)$ & 0.058 \\
\hline Preop radiation therapy & $3(1.3)$ & $3(1.6)$ & 1.000 \\
\hline Albumin & $3.7(0.58)$ & $3.84(0.56)$ & 0.024 \\
\hline Bilirubin & $1.94(3.12)$ & $1.92(3.72)$ & 0.494 \\
\hline Hematocrit & $36.64(5.72)$ & $38.39(5.11)$ & 0.007 \\
\hline INR & $1.11(0.15)$ & $1.12(0.24)$ & 0.586 \\
\hline Procedure duration (min) & $283.61(92.92)$ & $283.73(84.1)$ & 0.534 \\
\hline
\end{tabular}

SD: Standard deviation; BMI: body mass index; INR: international normalized ratio.

instructions about preoperative wellness. Overall patient reported compliance (partial or full) with the individual wellness components of the WP among both PD and DP groups was 55\%, and one third of patients completed all components of the WP. A nurse in the preoperative holding area handed out a sheet to the patients to selfreport compliance with each of the individual components of the bundle. Unfortunately, there were several barriers to receiving this information from patients the day of surgery. Moreover, the small sample of patients included in this study along with the insufficiently powered data were limiting factors to report a meaningful analysis of the effect of each individual component.

Statistical analysis. Chi-squared and t-tests were used to examine potential differences in perioperative variables. Potential confounders were included in multivariable logistic regression and Poisson regression (for modeling length of stay) models.

\section{Results}

Pancreatoduodenectomy (PD). Baseline characteristics were comparable between the groups (Table I). Enrollment in the WP was associated with a significant reduction in LOS from 
Table II. Post-operative course and outcomes for PD patients with and without enrollment in WP - univariable analysis.

\begin{tabular}{lccr}
\hline & \multicolumn{2}{c}{ PD Patients only } & \\
\cline { 2 - 3 } Covariate & $\begin{array}{c}\text { Non-WP } \\
(\mathrm{n}=223)\end{array}$ & $\begin{array}{c}\text { WP } \\
(\mathrm{n}=188)\end{array}$ & \\
& $\mathrm{n}(\%)$ & $\mathrm{n}(\%)$ & \\
\hline Deep SSI & $5(2.2)$ & $0(0)$ & 0.094 \\
Superficial SSI & $4(1.8)$ & $4(2.1)$ & 0.816 \\
DGE & $42(18.8)$ & $30(16)$ & 0.448 \\
Death & $6(2.7)$ & $3(1.6)$ & 0.473 \\
Organ SSI & $26(11.7)$ & $19(10.1)$ & 0.619 \\
Percutaneous drain(s) placed & $12(5.4)$ & $14(7.4)$ & 0.401 \\
Pneumonia & $6(2.7)$ & $6(3.2)$ & 0.771 \\
Septic shock & $9(4)$ & $5(2.7)$ & 0.459 \\
Needed postop transfusions & $69(30.9)$ & $44(23.4)$ & 0.090 \\
UTI & $5(2.2)$ & $4(2.1)$ & 0.940 \\
Vein thrombosis & $9(4)$ & $5(2.7)$ & 0.459 \\
Had related readmission & $34(15.2)$ & $18(9.6)$ & 0.090 \\
LOS [days, mean (SD)] & $12(10)$ & $9.6(8.0)$ & $<\mathbf{0 . 0 0 1}$ \\
\hline
\end{tabular}

SSI: Surgical site infection; UTI: urinary tract infection; LOS: length of stay. $p$-Values were obtained using logistic regression and negative binomial regression (for length of stay). Bold values indicate statistical significance.

12 to 9.6 days (Table II), univariable index ratio (IR) of 0.80 $(95 \% \mathrm{CI}=0.71-0.91, p<0.001)$. Participation in the program was also associated with trends toward decreased deep SSI ( $\mathrm{OR}=0.1, \mathrm{CI}=0.01-1.48, p=0.094)$, post-operative transfusions, $(\mathrm{OR}=0.68, \quad 95 \% \mathrm{CI}=0.44-1.06, p=0.090)$, and rates of readmission $(\mathrm{OR}=0.59,95 \% \mathrm{CI}=0.33-0.09, p=0.090)$ on univariable analysis. On multivariable analysis, only LOS continued to have significance $(\mathrm{OR}=0.85,95 \% \mathrm{CI}=0.77-0.94$, $p<0.001)$.

Distal pancreatectomy $(D P)$. Slight differences in baseline characteristics were noted between cohorts. Patients in the non-intervention group were more likely to have an open procedure (90 vs. 76.7\%, $p=0.003$ ), receive pre-operative chemotherapy (78 vs. 39.3\%, p<0.001), and radiation therapy (9.7 vs. $0 \%, p=0.024)$ (Table III). DP patients that received the WP were less likely to receive postoperative blood transfusion $(\mathrm{OR}=0.45,95 \% \mathrm{CI}=0.22-0.91, p=0.027)$ (Table IV). This finding-maintained significance on multivariable analysis $(\mathrm{OR}=0.38, \quad 95 \% \mathrm{CI}=0.19-0.9$, $p=0.027)$. There was a non-significant trend toward shorter LOS (7.3 vs. 6.5 days) on univariable analysis $(\mathrm{OR}=0.85$, $95 \% \mathrm{CI}=0.77-1.03, p=0.11)$.

Pancreatoduodenectomy and distal pancreatectomy combined. On combined assessment of all patients that underwent pancreatic resection, the two groups had comparable demo-
Table III. Comparison of demographics and perioperative variables for DP patients with and without enrollment in the WP.

\begin{tabular}{lccc}
\hline & \multicolumn{2}{c}{ Distal patients only } & \\
\cline { 2 - 3 } Covariate & $\begin{array}{c}\text { Non-WP } \\
(\mathrm{n}=138)\end{array}$ & $\begin{array}{c}\text { WP } \\
(\mathrm{n}=120)\end{array}$ & \\
& $\mathrm{n}(\%)$-V & $\mathrm{n}(\%)$ or & \\
& mean (SD) & mean (SD) & \\
\hline Age & $57.63(13.79)$ & $58.07(15.84)$ & 0.427 \\
BMI & $28.51(6.3)$ & $28.55(6.69)$ & 0.804 \\
Gender (male) & $69(50)$ & $57(47.5)$ & 0.707 \\
Race (non-white) & $13(9.4)$ & $13(10.8)$ & 0.838 \\
Diabetes & $34(24.6)$ & $36(30)$ & 0.400 \\
Hypertension & $71(51.4)$ & $53(44.2)$ & 0.265 \\
Steroid/Immunosuppressant Use & $3(2.2)$ & $1(0.8)$ & 0.622 \\
Weight loss $>10 \%$ & $11(8)$ & $18(15)$ & 0.078 \\
Received preop transfusion(s) & $3(2.2)$ & $0(0)$ & 0.251 \\
Open operative approach & $125(90.6)$ & $92(76.7)$ & $\mathbf{0 . 0 0 3}$ \\
Soft gland & $4(36.4)$ & $16(45.7)$ & 0.726 \\
Preop chemotherapy & $99(78)$ & $46(39.3)$ & $<\mathbf{0 . 0 0 1}$ \\
Preop radiation therapy & $3(9.7)$ & $0(0)$ & $\mathbf{0 . 0 2 4}$ \\
Albumin & $3.97(0.55)$ & $4.01(0.54)$ & 0.527 \\
Bilirubin & $0.53(0.27)$ & $0.52(0.26)$ & 0.828 \\
Hematocrit & $38.49(5.87)$ & $39.2(5.31)$ & 0.337 \\
INR & $1.09(0.15)$ & $1.14(0.22)$ & $\mathbf{0 . 0 0 9}$ \\
Procedure duration (min) & $189.91(59.63)$ & $183.24(64.83)$ & 0.285 \\
\hline & & & \\
\hline
\end{tabular}

BMI: Body mass index; INR: international normalized ratio. Bold values indicate statistical significance.

graphics with regards to gender, age, race, ethnicity, and ASA. In comparison to patients in the WP, controls were more likely to have required pre-operative transfusion $(2.2 \mathrm{vs} .0 .2 \%$, $p=0.013)$, presented with jaundice (32.1 vs. $22.3 \%, p=0.014)$, and/ or received pre-operative chemotherapy (36.9 vs. $27.9 \%$, $p=0.017)$. On univariable analysis, implementation of the WP was associated with a significant decrease in LOS (10.2 vs. 8.4 days, $p<0.001)$, less post-operative transfusion requirements $(\mathrm{OR}=0.61,95 \% \mathrm{CI}=0.42-0.88, p=0.008)$, and a trend towards decreased deep SSIs $(\mathrm{OR}=0.08,95 \% \mathrm{CI}=0.01$ $1.12, p=0.061)$ and readmission rates $(\mathrm{OR}=0.68,95 \% \mathrm{CI}=0.43-$ $1.08, p=0.107)$. On multivariable analysis, LOS continued to maintain statistical significance $(\mathrm{IR}=0.89,95 \% \mathrm{CI}=0.82-0.97$, $p<0.007)$.

\section{Discussion}

Enhanced recovery after surgery (ERAS) protocols are associated with improved outcomes and shorter length of stay $(18,19)$. The ERAS Group published guidelines for colorectal procedures, which are widely accepted (19) and similar protocols have been applied to other surgical specialties including plastics, orthopedics, gynecologic oncology, foregut, and liver surgery (19-22). A growing body of literature 
Table IV. Post-operative course and outcomes for DP patients with and without enrollment in WP - univariable analysis.

\begin{tabular}{lccr}
\hline & \multicolumn{2}{c}{ Distal patients only } & \\
\cline { 2 - 3 } Covariate & $\begin{array}{c}\text { Non-WP } \\
(\mathrm{n}=138)\end{array}$ & $\begin{array}{c}\text { WP } \\
(\mathrm{n}=120)\end{array}$ & \\
& $\mathrm{n}(\%)$ & $\mathrm{n}(\%)$ & \\
\hline Deep SSI & $2(1.4)$ & $0(0)$ & 0.287 \\
Superficial SSI & $1(0.7)$ & $1(0.8)$ & 0.932 \\
DGE & $2(7.1)$ & $2(2.6)$ & 0.897 \\
Death & $2(1.4)$ & $2(1.7)$ & 0.897 \\
Organ SSI & $15(10.9)$ & $8(6.7)$ & 0.249 \\
Percutaneous drain(s) placed & $4(14.3)$ & $6(7.9)$ & 0.354 \\
Pneumonia & $6(4.3)$ & $1(0.8)$ & 0.123 \\
Septic shock & $3(2.2)$ & $2(1.7)$ & 0.783 \\
Needed postop transfusions & $28(20.3)$ & $12(10)$ & $\mathbf{0 . 0 2 7}$ \\
UTI & $0(0)$ & $5(4.2)$ & 0.058 \\
Had related readmission & $20(14.5)$ & $15(12.5)$ & 0.645 \\
LOS [days, mean (SD)] & $7.3(6.2)$ & $6.5(3.9)$ & $<0.111$ \\
\hline
\end{tabular}

SSI: Surgical site infection; UTI: urinary tract infection: LOS: length of stay. Bold values indicate statistical significance.

supports implementation of ERAS for pancreatic surgery; however, many pancreatic surgeons have been slow to incorporate these protocols. A prospective trial and metaanalysis with 3,700 pancreatectomy patients reported improved patient outcomes and/or decreased length of stay with implementation of ERAS protocol focused on early alimentation, drain removal, and minimization of narcotics and intravenous fluids (23-27). The effect of the WP has been previously established on a large scale across multiple surgical specialties at our institution; implementation was associated with a reduction in post-operative complications such as SSIs, particularly among patients with ASA score of 3 or higher (28). The present study focused on pancreatic surgery patients in the preoperative settings and demonstrated expedited recovery.

A multimodality pre-operative rehabilitation program assesses patients physiologic reserve through analysis of acute/chronic medical conditions as well as nutritional status. In the present study, acute/chronic medical conditions were identified during the PAT Clinic visit for each patient enrolled in the WP and referrals made to medical subspecialty clinics when needed. In addition, these patients were educated about the importance of increasing daily physical activities, avoiding modifiable risk factors such as smoking/alcohol cessation and individual components of a wellness bundle. Although a bundled approach to quality improvement initiatives is challenged by difficulties in discerning the impact of each component, the educational meeting and referral process likely played very important roles in patient outcome.
Additionally, when considering specific components of the red bag, the immuno-nutrition drink (ID) emerges as a strong candidate in the present study for the following reasons. Malnutrition is prevalent among pancreatic surgery patients and is marked by the presence of dysfunctional T-cells, coagulopathy, as well as deconditioning after surgery. Invasive surgery is associated with suppression of helper $\mathrm{T}$ cell activity and cytokine production (14, 29, 30). Supplemental ID has been postulated to modulate postoperative changes, potentially ameliorating the impact of surgical stress on T-cell impairment (14). Several studies have demonstrated improved postoperative outcomes and decreased length of stay with ID $(14,23-27,31)$. Furthermore, the immuno-nutrition drink used in the current study contains arginine, a conditionally essential amino acid. Although arginine is synthesized by a variety of body cell types, endogenous synthesis may not meet cellular demand in highly stressful conditions experienced after major surgeries. Arginine supports the immune system by promoting T-cell growth and replication; in addition, it is a precursor for nitrous oxide (NO), which increases gut oxygenation and micro-perfusion (14). Another key ingredient in the immuno-nutrition drink is essential fatty acids such as linoleic and linolenic acid, provided in the form of Omega-3 \& 6, respectively. Omega fatty acids preserve intestinal integrity and decrease injury from peritoneal air exposure, which in turn would mitigate the systematic inflammatory response in the post-operative setting. Tan and colleagues established a direct correlation between the duration of peritoneal air exposure and mucosal barrier injury using animal models (32). Finally, the immunenutrition drink contains nucleotides, which can serve as building blocks for active DNA and RNA replication during cellular regeneration in post-operative periods. There have been multiple studies reporting positive outcomes with nutritional status optimization in pancreatic surgery patients (33-35). However, ERAS Society has rated the level of evidence for the application of immune-nutrition to pancreatic patients as moderate, with a low recommendation to its application (36). The moderate level of evidence leaves the door open for studies such ours to assess the utility of immune-nutrition drinks. The "low" rated recommendation could be explained by the variability of the commercially available products evaluated. The drink used in the present study, to our knowledge, is the only validated drink with the three key ingredients detailed above.

In our study, the WP was extremely cost effective. The cost of the bundled components was estimated at fifty dollars per patient $(n=308)$, bringing the overall cost to $\$ 15,400$. A one-day delay in discharge at our institution has an estimated cost of $\$ 1,600$. We report that patients who received the WP and underwent PD $(n=188)$ stayed in the hospital on average 2.4 days less. Adjusting the calculations to the nearest 
decimal change for an average two days difference brings the total cost savings to approximately $\$ 601,600$.

We also analyzed the effect of the WP on major liver resections and observed similar trends (unpublished results). Specifically, we found consistency in the reduction of LOS, as well as post-operative blood transfusion requirements. These results suggest that the WP should also be considered for potential application to hepatobiliary surgeries. In support, a reduction in LOS, as well as overall complications, has been previously reported in a systematic review of the effect of ERAS on liver resections (37).

This study has several limitations. First, intervention and control groups were not randomized nor matched, which introduces the possibility of selection bias. However, the intervention group was characterized as having comorbidities prompting a referral by the operating surgeon to the PAT Clinic. Next, detailed compliance data were not available, limiting our ability to investigate the effect that each individual component had on the outcome. Moreover, the number of patients evaluated would likely limit the statistical power of individual component analysis. Finally, despite collecting data prospectively, our study was non-randomized, retrospective and from a single institution. Understanding these limitations, future goals will be targeted toward achieving more efficient and convenient timing for WP counseling, maximizing delivery of WP instructions to optimize compliance, and developing a more reliable method of reporting compliance.

\section{Conclusion}

Adoption of a novel, preoperative, patient-centered WP can improve outcomes for pancreatic surgery patients by reducing postoperative infectious complications, blood transfusion requirements, as well as LOS. Future efforts should focus on delivering the care within a timeframe that maximizes efficacy, ideally remotely using technology such as video-assistive devices, as well as optimizing compliance among pancreatic surgery patients.

\section{Conflicts of Interest}

The Authors have no conflicts of interest to disclose regarding this study.

\section{Authors' Contributions}

Soufi, DePeralta, Schmidt: conception/design of the work; data acquisition, analysis, interpretation; manuscript drafting/revision/final approval; agreement to accountability. Simpson, Flick, Yip-Schneider, Schmidt II, Kilbane, Kelley, Wooden, Ceppa, House, Zyromski, Nakeeb: Data acquisition, interpretation; manuscript revision/final approval; agreement to accountability. Colgate: Data analysis, interpretation; manuscript revision/final approval; agreement to accountability.

\section{Acknowledgements}

No external financial support or grant funding was used in this research study.

\section{References}

1 Whipple AO, Parsons WB and Mullins CR: Treatment of carcinoma of the ampulla of vater. Ann Surg 102(4): 763-779, 1935. PMID: 17856666. DOI: 10.1097/00000658-19351000000023

2 de Wilde RF, Besselink MG, van der Tweel I, de Hingh IH, van Eijck CH, Dejong CH, Porte RJ, Gouma DJ, Busch OR, Molenaar IQ and Dutch Pancreatic Cancer Group.: Impact of nationwide centralization of pancreaticoduodenectomy on hospital mortality. Br J Surg 99(3): 404-410, 2012. PMID: 22237731. DOI: $10.1002 /$ bjs.8664

3 Morikane K: Epidemiology and risk factors associated with surgical site infection after different types of hepatobiliary and pancreatic surgery. Surg Today 47(10): 1208-1214, 2017. PMID: 28303341. DOI: $10.1007 / \mathrm{s} 00595-017-1503-0$

4 Balzano G, Zerbi A, Capretti G, Rocchetti S, Capitanio V and Di Carlo V: Effect of hospital volume on outcome of pancreaticoduodenectomy in Italy. Br J Surg 95(3): 357-362, 2008. PMID: 17933001. DOI: 10.1002/bjs.5982

5 Anderson DJ, Podgorny K, Berríos-Torres SI, Bratzler DW, Dellinger EP, Greene L, Nyquist AC, Saiman L, Yokoe DS, Maragakis LL and Kaye KS: Strategies to prevent surgical site infections in acute care hospitals: 2014 update. Infect Control Hosp Epidemiol 35(6): 605-627, 2014. PMID: 24799638. DOI: $10.1086 / 676022$

6 Ban KA, Minei JP, Laronga C, Harbrecht BG, Jensen EH, Fry DE, Itani KM, Dellinger EP, Ko CY and Duane TM: American College of Surgeons and Surgical Infection Society: Surgical site infection guidelines, 2016 update. J Am Coll Surg 224(1): 59-74, 2017. PMID: 27915053. DOI: 10.1016/j.jamcollsurg.2016.10.029

7 de Lissovoy G, Fraeman K, Hutchins V, Murphy D, Song D and Vaughn BB: Surgical site infection: Incidence and impact on hospital utilization and treatment costs. Am J Infect Control 37(5): 387-397, 2009. PMID: 19398246. DOI: 10.1016/j.ajic.2008.12.010

8 Awad SS, Palacio CH, Subramanian A, Byers PA, Abraham P, Lewis DA and Young EJ: Implementation of a methicillin-resistant Staphylococcus aureus (MRSA) prevention bundle results in decreased MRSA surgical site infections. Am J Surg 198(5): 607610, 2009. PMID: 19887186. DOI: 10.1016/j.amjsurg.2009.07.010

9 Perl TM, Cullen JJ, Wenzel RP, Zimmerman MB, Pfaller MA, Sheppard D, Twombley J, French PP, Herwaldt LA and Mupirocin And The Risk Of Staphylococcus Aureus Study Team.: Intranasal mupirocin to prevent postoperative Staphylococcus aureus infections. N Engl J Med 346(24): 18711877, 2002. PMID: 12063371. DOI: 10.1056/NEJMoa003069

10 Truntzer J, Vopat B, Feldstein M and Matityahu A: Smoking cessation and bone healing: Optimal cessation timing. Eur J Orthop Surg Traumatol 25(2): 211-215, 2015. PMID: 24879610. DOI: $10.1007 /$ s00590-014-1488-y

11 Basoglu OK, Atasever A and Bacakoglu F: The efficacy of incentive spirometry in patients with COPD. Respirology 10(3): 349-353, 2005. PMID: 15955148. DOI: 10.1111/j.1440$1843.2005 .00716 . \mathrm{x}$ 
12 Sebio Garcia R, Yáñez Brage MI, Giménez Moolhuyzen E, Granger CL and Denehy L: Functional and postoperative outcomes after preoperative exercise training in patients with lung cancer: A systematic review and meta-analysis. Interact Cardiovasc Thorac Surg 23(3): 486-497, 2016. PMID: 27226400. DOI: $10.1093 /$ icvts/ivw152

13 Marik PE and Zaloga GP: Immunonutrition in high-risk surgical patients: A systematic review and analysis of the literature. JPEN J Parenter Enteral Nutr 34(4): 378-386, 2010. PMID: 20631383. DOI: $10.1177 / 0148607110362692$

14 Drover JW, Dhaliwal R, Weitzel L, Wischmeyer PE, Ochoa JB and Heyland DK: Perioperative use of arginine-supplemented diets: A systematic review of the evidence. J Am Coll Surg 212(3): 385-99, 399.e1, 2011. PMID: 21247782. DOI: 10.1016/ j.jamcollsurg.2010.10.016

15 Augustin T, Burstein MD, Schneider EB, Morris-Stiff G, Wey J, Chalikonda $\mathrm{S}$ and Walsh RM: Frailty predicts risk of lifethreatening complications and mortality after pancreatic resections. Surgery 160(4): 987-996, 2016. PMID: 27545992. DOI: $10.1016 /$ j.surg.2016.07.010

16 Wente MN, Bassi C, Dervenis C, Fingerhut A, Gouma DJ, Izbicki JR, Neoptolemos JP, Padbury RT, Sarr MG, Traverso LW, Yeo CJ and Büchler MW: Delayed gastric emptying (DGE) after pancreatic surgery: A suggested definition by the International Study Group of Pancreatic Surgery (ISGPS). Surgery 142(5): 761-768, 2007. PMID: 17981197. DOI: 10.1016/j.surg.2007.05.005

17 Bassi C, Marchegiani G, Dervenis C, Sarr M, Abu Hilal M, Adham M, Allen P, Andersson R, Asbun HJ, Besselink MG, Conlon K, Del Chiaro M, Falconi M, Fernandez-Cruz L, Fernandez-Del Castillo C, Fingerhut A, Friess H, Gouma DJ, Hackert T, Izbicki J, Lillemoe KD, Neoptolemos JP, Olah A, Schulick R, Shrikhande SV, Takada T, Takaori K, Traverso W, Vollmer CR, Wolfgang CL, Yeo CJ, Salvia R, Buchler M and International Study Group on Pancreatic Surgery (ISGPS).: The 2016 update of the International Study Group (ISGPS) definition and grading of postoperative pancreatic fistula: 11 years after. Surgery 161(3): 584-591, 2017. PMID: 28040257. DOI: 10.1016/j.surg.2016.11.014

18 Wind J, Polle SW, Fung Kon Jin PH, Dejong CH, von Meyenfeldt MF, Ubbink DT, Gouma DJ, Bemelman WA, Laparoscopy and/or Fast Track Multimodal Management Versus Standard Care (LAFA) Study Group and Enhanced Recovery after Surgery (ERAS) Group.: Systematic review of enhanced recovery programmes in colonic surgery. Br J Surg 93(7): 800809, 2006. PMID: 16775831. DOI: 10.1002/bjs.5384

19 Gustafsson UO, Scott MJ, Schwenk W, Demartines N, Roulin D, Francis N, McNaught CE, MacFie J, Liberman AS, Soop M, Hill A, Kennedy RH, Lobo DN, Fearon K, Ljungqvist $\mathrm{O}$ and Enhanced Recovery After Surgery Society.: Guidelines for perioperative care in elective colonic surgery: Enhanced Recovery After Surgery (ERAS ${ }^{\circledR}$ ) Society recommendations. Clin Nutr 31(6): 783-800, 2012. PMID: 23099039. DOI: 10.1016/j.clnu.2012.08.013

20 Zhao Y, Qin H, Wu Y and Xiang B: Enhanced recovery after surgery program reduces length of hospital stay and complications in liver resection: A PRISMA-compliant systematic review and meta-analysis of randomized controlled trials. Medicine (Baltimore) 96(31): e7628, 2017. PMID: 28767578. DOI: 10.1097/MD.0000000000007628
21 Kaoutzanis C, Ganesh Kumar N, O’Neill D, Wormer B, Winocour J, Layliev J, McEvoy M, King A, Braun SA and Higdon KK: Enhanced Recovery Pathway in Microvascular Autologous TissueBased Breast Reconstruction: Should It Become the Standard of Care? Plast Reconstr Surg 141(4): 841-851, 2018. PMID: 29465485. DOI: 10.1097/PRS.0000000000004197

22 Gherini S, Vaughn BK, Lombardi AV Jr and Mallory TH: Delayed wound healing and nutritional deficiencies after total hip arthroplasty. Clin Orthop Relat Res (293): 188-195, 1993. PMID: 8339480

$23 \mathrm{Hu}$ ZC, He LJ, Chen D, Li XB, Feng ZH, Fu CW, Xuan JW, Ni WF and Wu AM: An enhanced recovery after surgery program in orthopedic surgery: A systematic review and meta-analysis. J Orthop Surg Res 14(1): 77, 2019. PMID: 30866978. DOI: 10.1186/s13018-019-1116-y

24 Ji HB, Zhu WT, Wei Q, Wang XX, Wang HB and Chen QP: Impact of enhanced recovery after surgery programs on pancreatic surgery: A meta-analysis. World J Gastroenterol 24(15): 16661678, 2018. PMID: 29686474. DOI: 10.3748/wjg.v24.i15.1666

25 Kagedan DJ, Ahmed M, Devitt KS and Wei AC: Enhanced recovery after pancreatic surgery: A systematic review of the evidence. HPB (Oxford) 17(1): 11-16, 2015. PMID: 24750457. DOI: $10.1111 / \mathrm{hpb} .12265$

26 Coolsen MM, van Dam RM, Chigharoe A, Olde Damink SW and Dejong $\mathrm{CH}$ : Improving outcome after pancreaticoduodenectomy: Experiences with implementing an enhanced recovery after surgery (ERAS) program. Dig Surg 31(3): 177-184, 2014. PMID: 25097014. DOI: $10.1159 / 000363583$

27 Agarwal V, Thomas MJ, Joshi R, Chaudhari V, Bhandare M, Mitra A, deSouza A, Ambulkar R and Shrikhande SV: Improved outcomes in 394 pancreatic cancer resections: the impact of enhanced recovery pathway. J Gastrointest Surg 22(10): 17321742, 2018. PMID: 29777454. DOI: 10.1007/s11605-018-3809-7

28 Kennedy EP, Grenda TR, Sauter PK, Rosato EL, Chojnacki KA, Rosato FE Jr, Profeta BC, Doria C, Berger AC and Yeo CJ: Implementation of a critical pathway for distal pancreatectomy at an academic institution. J Gastrointest Surg 13(5): 938-944, 2009. PMID: 19190968. DOI: 10.1007/s11605-009-0803-0

29 Kelley KE, Fajardo AD, Strange NM, Harmon CA, Pawlecki K, Sieber M, Walke N, Fadel WF, Wooden WA, Sadowski J, Birdas TJ, Stevens LH, Rozycki GS and Schmidt CM: Impact of a novel preoperative patient-centered surgical wellness program. Ann Surg 268(4): 650-656, 2018. PMID: 30138164. DOI: 10.1097/SLA.0000000000002932

30 Ishibashi S, Takeuchi H, Fujii K, Shiraishi N, Adachi Y and Kitano S: Length of laparotomy incision and surgical stress assessed by serum IL-6 level. Injury 37(3): 247-251, 2006. PMID: 16434039. DOI: 10.1016/j.injury.2005.08.008

31 La Torre M, Ziparo V, Nigri G, Cavallini M, Balducci G and Ramacciato G: Malnutrition and pancreatic surgery: Prevalence and outcomes. J Surg Oncol 107(7): 702-708, 2013. PMID: 23280557. DOI: $10.1002 /$ jso.23304

32 Tan S, Yu W, Lin Z, Chen Q, Shi J, Dong Y, Duan K, Bai X, Xu $\mathrm{L}, \mathrm{Li} \mathrm{J}$ and $\mathrm{Li} \mathrm{N}$ : Peritoneal air exposure elicits an intestinal inflammation resulting in postoperative ileus. Mediators Inflamm 2014: 924296, 2014. PMID: 25140117. DOI: $10.1155 / 2014 / 924296$

33 Schnelldorfer T and Adams DB: The effect of malnutrition on morbidity after surgery for chronic pancreatitis. Am Surg 71(6): 466-472; discussion 472-473, 2005. PMID: 16044924. 
34 Kanda M, Fujii T, Kodera Y, Nagai S, Takeda S and Nakao A: Nutritional predictors of postoperative outcome in pancreatic cancer. Br J Surg 98(2): 268-274, 2011. PMID: 20960457. DOI: 10.1002/bjs.7305

35 Probst P, Haller S, Bruckner T, Ulrich A, Strobel O, Hackert T, Diener MK, Büchler MW and Knebel P: Prospective trial to evaluate the prognostic value of different nutritional assessment scores in pancreatic surgery (NURIMAS Pancreas). Br J Surg 104(8): 1053-1062, 2017. PMID: 28369809. DOI: 10.1002/ bjs. 10525

36 Lassen K, Coolsen MM, Slim K, Carli F, de Aguilar-Nascimento JE, Schäfer M, Parks RW, Fearon KC, Lobo DN, Demartines N, Braga M, Ljungqvist O, Dejong CH, ERAS ${ }^{\circledR}$ Society., European Society for Clinical Nutrition and Metabolism. and International
Association for Surgical Metabolism and Nutrition.: Guidelines for perioperative care for pancreaticoduodenectomy: Enhanced Recovery After Surgery (ERAS ${ }^{\circledR}$ ) Society recommendations. Clin Nutr 31(6): 817-830, 2012. PMID: 23079762. DOI: 10.1016/j.clnu.2012.08.011

37 Wang C, Zheng G, Zhang W, Zhang F, Lv S, Wang A and Fang $\mathrm{Z}$ : Enhanced recovery after surgery programs for liver resection: A meta-analysis. J Gastrointest Surg 21(3): 472-486, 2017. PMID: 28101720. DOI: 10.1007/s11605-017-3360-y

Received February 3, 2021

Revised February 23, 2021

Accepted February 24, 2021 